\title{
The first combined meta-analytic approach for elucidating the relationship of circulating resistin levels and RETN gene polymorphisms with colorectal and breast cancer
}

\author{
Md. Abdul Aziz ${ }^{1,2}$, Tahmina Akter ${ }^{1,2}$, Md. Shahid Sarwar ${ }^{1,2}$ and Mohammad Safiqul Islam ${ }^{1,2^{*}}$ (D)
}

\begin{abstract}
Background: Evidence suggests that circulating resistin levels are altered in colorectal cancer (CRC) and breast cancer (BC). Again, polymorphisms in resistin-encoding gene RETN have been evaluated in CRC and BC. However, there is a scarcity of data establishing the relationship of resistin and RETN polymorphisms (rs1862513 and rs3745367) with these cancers. This study aimed to analyze the relationship of resistin levels and RETN polymorphisms with CRC and $\mathrm{BC}$ in a combined meta-analytic approach.
\end{abstract}

Main body of the abstract: After a comprehensive online literature search, screening and eligibility check, 41 articles (31 with resistin level and 10 with RETN polymorphisms) were retrieved for meta-analyses. The mean difference (MD) of resistin was calculated and pooled to investigate the effect sizes with a $95 \%$ confidence interval (Cl), and the connection of genetic polymorphisms was analyzed with an odds ratio (OR) and $95 \% \mathrm{Cl}$. The analysis showed that resistin level is significantly higher in $C R C(M D=3.39)$ and $B C(M D=3.91)$ patients. Subgroup analysis in $C R C$ showed significantly higher resistin in serum $(M D=4.61)$ and plasma $(M D=0.34)$, and in $B C$, a significantly elevated resistin level was reported in premenopausal $(M D=7.82)$ and postmenopausal $(M D=0.37)$ patients. Again, RETN rs 1862513 showed a significantly strong association with CRC (codominant 1-OR 1.24, codominant 2-OR 1.31, dominant model-OR 1.25, and allele model-OR 1.16) and with BC (codominant 2-OR 1.51, codominant 3-OR 1.51, recessive model -OR 1.51, and allele model-OR 1.21). RETN rs3745367 did not show any association with these cancers.

Short conclusion: Overall, our analysis indicates that higher circulating resistin levels are associated with an elevated risk of CRC and premenopausal and postmenopausal BC. Besides, rs1862513 in RETN gene is significantly connected with both CRC and BC.

Keywords: Resistin, RETN, Breast cancer, Colorectal cancer, Meta-analysis

\section{Background}

Colorectal cancer (CRC) is a frequently occurred malignancy throughout the world. It is consistently placed among the top three cancers based on morbidity and mortality rates $[1,2]$. It is a public health concern

\footnotetext{
*Correspondence: research_safiq@yahoo.com

1 Department of Pharmacy, Faculty of Science, Noakhali Science and Technology University, Sonapur 3814, Noakhali, Bangladesh Full list of author information is available at the end of the article
}

worldwide, particularly in developed countries, where the incidence rate (about 18\%) is higher than the developing or under-developed countries. In the past few decades, the percentage of CRC cases are rapidly increasing in developing regions. This is considered a complex multi-pathway malignancy associated with a chronic inflammatory reaction, metabolic syndrome, obesity, and insulin resistance. Recent evidence suggests that adipocyte-secreted factors such as resistin, adiponectin, visfatin, leptin, and various cytokines (IL-6, IL-10, TNF- $\alpha$, 
etc.) may play the key role to correlate obesity with CRC $[3,4]$.

In terms of incidence, breast cancer (BC) has been the leading malignancy among women worldwide. It is also one of the commonest causes of mortality, comprising almost $6.6 \%$ of all cancer-related deaths. Statistics showed that about 2.1 million $\mathrm{BC}$ cases were recorded in 2018, leading to the death of 626,679 patients $[5,6]$. $\mathrm{BC}$ is a heterogeneous and polygenic multifactorial disease that occurs due to the combined effect of multiple factors, including genetic and epigenetic abnormalities, unhealthy lifestyle, and environmental pollutants [7]. Taking high-fat diets, physical inactivity, early menstrual cycle, late menopause, denser breast tissues, age, hormonal imbalance or exogenous hormone therapy, radiation therapy, high mental stress, and exposure to environmental pollutants are the common causes of $\mathrm{BC}$ [8].

Resistin, also known as an adipocyte-secreted factor, is a $12.5 \mathrm{kDa}$ cysteine-rich 108-amino-acid peptide adipocytokine secreted by adipocytes and monocytes [9]. This inflammatory protein was first identified in mice adipose tissue and subsequently named resistin due to its role in insulin resistance [10]. Translational studies revealed that human resistin is primarily secreted from macrophages rather than from adipocytes [11]. The adipokine resistin belongs to the family of resistin-like molecules (RELM) and is commonly localized in inflammatory zone $3[10$, 12]. Resistin is one of the most common candidate molecules that play a significant role in numerous physiological and pathological processes in human body. Accumulating evidence suggests that this cytokine exhibits inflammatory, autoimmune, metabolic, proliferative, angiogenic, and metastatic properties via multiple cellular and molecular pathways $[1,13]$.

Although resistin was initially investigated for a functional role in insulin resistance and obesity, its diverse role in different diseases has drawn the concentration of researchers, making it one of the most studied biomarkers. Serum levels of resistin have been implicated in the occurrence and progression of various inflammatory processes, such as atherosclerosis, diabetes mellitus, metabolic syndrome, non-alcoholic fatty liver disease, inflammatory bowel disease, rheumatic arthritis, and malignant tumors $[1,13,14]$. Elevated concentration of resistin in plasma acts as a prognostic biomarker in the progression and metastasis of breast, colorectal, ovarian, pancreatic, lung, endometrial, prostate, and other obesity-related cancers in human. High serum resistin level was also found to be strongly associated with tumor stage and poor survival $[15,16]$. Previous studies reported a significantly higher concentration of serum resistin in $\mathrm{BC}$ patients. Moreover, enhanced expression of serum resistin in $\mathrm{BC}$ tissues was found to be correlated with postmenopausal $\mathrm{BC}$ and poor tumor prognosis [17]. Again, increased circulating resistin levels in CRC have also been documented by previous studies. However, there is a gap in the consistency of previously published results on the association of serum resistin level with $\mathrm{BC}$ and CRC risk, which should be clarified.

Resistin is encoded by RETN, an important adipocytokine gene located on chromosome 9 (19p13.3) and mainly expressed in adipocytes $[18,19]$. Previous investigations on RETN genetic polymorphisms reported their strong correlation with circulating resistin levels, RETN expression, and body mass index (BMI) [20, 21]. Single nucleotide polymorphisms (SNPs) are generally spotted in the promoter region and 3'-untranslated region of RETN [22]. Common SNPs in the RETN gene, including promoter rs1862513 (C-180G/ C-420G) and rs3745367 $(\mathrm{G}+299 \mathrm{~A})$, have been previously analyzed for their contribution to the progression of several diseases, including CRC $[19,21,23-25]$ and BC $[18,22]$. However, the outcomes of these studies remained conflicting and need to be re-evaluated.

To date, numerous case-control studies have been carried out in different ethnic groups to examine the correlation of resistin levels and RETN gene polymorphisms with multiple cancers, especially with CRC and BC. However, these findings remained inconclusive and inconsistent. To our knowledge, no previous systemic review and meta-analysis was conducted to evaluate the relationship between both circulatory resistin and RETN gene polymorphisms and these cancers. Therefore, we performed the first combined meta-analyses to establish a comprehensive relationship of resistin levels in serum or plasma and RETN genetic polymorphisms with CRC and $\mathrm{BC}$.

\section{Results}

\section{Description of the included studies}

Our literature search generated a total of 2674 publications in PubMed, ScienceDirect, BMC, EMBASE, Cochrane Library, Web of Science, and Google Scholar databases for both meta-analyses shown in Fig. 1. Following the removal of duplicates and studies analyzing biomarkers other than resistin and polymorphisms other than RETN, 579 records remained for the title and abstract screening. Due to the lack of full-text access and excluding reviews, commentaries, or studies with inadequate data, 41 articles remained for both qualitative and quantitative analysis (meta-analysis) among which 31 for resistin level and 10 for RETN genetic association.

Of 31 articles with resistin levels, a total of 16 studies were on CRC [11, 25-39], and 15 studies were on BC [18, 40-53]. Among the 16 studies on CRC, 9 studies [25-33] analyzed the serum resistin in $382 \mathrm{CRC}$ cases 


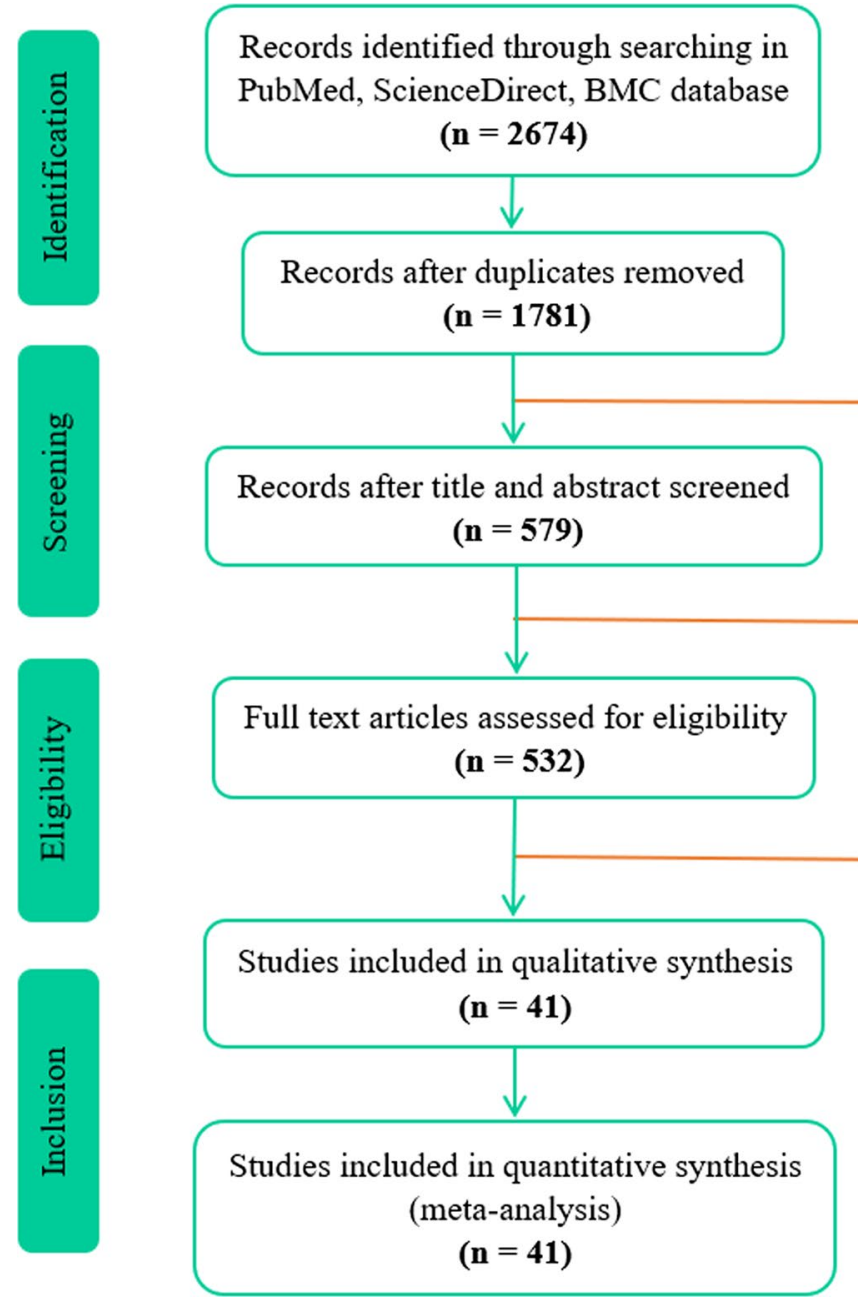

Fig. 1 Flow diagram of the literature search and study selection for the meta-analysis

and 367 controls, whereas 7 studies [11, 34-39] analyzed the plasma resistin in 1199 CRC cases and 1492 controls. Again, among 15 studies in analyzing resistin level in $2132 \mathrm{BC}$ patients and 1780 controls, only two studies $[24,51]$ analyzed the plasma resistin level in 916 cases and 864 controls, while 13 studies [18, 40-48, 50, 52, 53] analyzed serum resistin level in 1216 cases and 916 controls. The characteristics of the selected studies evaluating resistin level with CRC and $\mathrm{BC}$ are summarized in Tables 1 and 2, respectively.

Again, of 41 studies, 10 studies evaluated the association of RETN gene polymorphisms with CRC and BC. Six studies examined the association of rs 1862513 on CRC $[19,21,24,25,38,54]$ and 3 studies examined the correlation of rs1862513 on $\mathrm{BC}[18,22,55]$ that included a total of 2095 cases and 2385 controls. For rs3745367, only three eligible studies were found with 747 cases and
791 controls, among which two studies were on CRC [21, $23]$ and one with $\mathrm{BC}$ [22]. Table 3 represents the characteristics of selected studies evaluating RETN gene polymorphisms.

\section{Meta-analysis of resistin levels and link with CRC and BC}

According to our meta-analysis of 31 studies, the levels of resistin in both CRC and BC patients are significantly higher than those in the control groups, as illustrated in Figs. 2 and 3, respectively. The results of the metaanalysis revealed that the resistin level was significantly higher in CRC patients than in controls when using a random effect model $(\mathrm{MD}=3.39,95 \% \mathrm{CI}=2.23-4.54$, $p<0.00001)$. Again, in terms of $\mathrm{BC}$, patients had a significantly higher level of resistin than controls $(\mathrm{MD}=3.91$, 95\% $\mathrm{CI}=1.12-6.71, p=0.006)$ and the difference was statistically significant. 
Table 1 Characteristics of the selected studies evaluating resistin level with colorectal cancer in the meta-analysis

\begin{tabular}{|c|c|c|c|c|c|c|c|}
\hline \multirow[t]{2}{*}{ Study ID } & \multirow[t]{2}{*}{ Country } & \multirow[t]{2}{*}{ Cases/controls } & \multirow[t]{2}{*}{ Assay type } & \multirow[t]{2}{*}{ Kit provider } & \multicolumn{2}{|c|}{$\begin{array}{l}\text { Mean resistin level (ng/ } \\
\mathrm{ml}) \pm \mathrm{SD}\end{array}$} & \multirow[t]{2}{*}{ NOS score } \\
\hline & & & & & Cases & Controls & \\
\hline \multicolumn{8}{|l|}{ Serum } \\
\hline Al-Harithy et al. [25] & KSA & $60 / 60$ & ELISA kit & ALPCO Diagnostic & $19.44 \pm 8.46$ & $5.45 \pm 2.73$ & 7 \\
\hline Danese et al. [26] & Italy & $40 / 40$ & ELISA kit & Mediagnost & $9.99 \pm 15.76$ & $4.98 \pm 4.92$ & 8 \\
\hline Gonullu et al. [27] & Turkey & $36 / 37$ & ELISA kit & BioSource & $6.1 \pm 3.3$ & $4.5 \pm 1.5$ & 8 \\
\hline Joshi et al. [28] & South Korea & $100 / 100$ & ELISA kit & Adipogen & $4.9 \pm 2.3$ & $2.8 \pm 1.7$ & 8 \\
\hline Kosova et al. [29] & Turkey & $20 / 20$ & ELISA kit & Millipore Corporation & $4.92 \pm 2.2$ & $3.39 \pm 1.1$ & 7 \\
\hline Kumor et al. [30] & Poland & $36 / 25$ & ELISA kit & R\&D Systems & $6.79 \pm 2.41$ & $3.6 \pm 1.08$ & 7 \\
\hline Lu et al. [31] & China & $30 / 30$ & ELISA kit & $A D L$ & $7.72 \pm 2.6$ & $7.42 \pm 3.72$ & 7 \\
\hline Shafik et al. [32] & Egypt & $30 / 25$ & ELISA kit & AssayMax ${ }^{\mathrm{TM}}$ & $18.86 \pm 2.6$ & $9.55 \pm 1.4$ & 7 \\
\hline Tulubas et al. [33] & Turkey & $30 / 30$ & ELISA kit & AssayMax ${ }^{\mathrm{TM}}$ & $18.77 \pm 5.09$ & $13.36 \pm 6.36$ & 8 \\
\hline Total & & $382 / 367$ & & & & & \\
\hline \multicolumn{8}{|l|}{ Plasma } \\
\hline Farahani et al. [34] & Iran & $82 / 88$ & ELISA kit & ZellBio & $5.7 \pm 1.2$ & $5.4 \pm 1.3$ & 8 \\
\hline Hillenbrand et al. [35] & Germany & $67 / 60$ & Multiplex Assay & Millipore & $19.53 \pm 29.58$ & $13.63 \pm 14.96$ & 7 \\
\hline Ho et al. [36] & USA & $456 / 834$ & Multiplex Assay & Millipore & $13.03 \pm 4.83$ & $12.57 \pm 4.31$ & 8 \\
\hline Mihajlovic et al. [11] & Serbia & $86 / 75$ & ELISA kit & R\&D Systems & $20.72 \pm 10.62$ & $12.08 \pm 7.58$ & 7 \\
\hline Nakajima et al. [37] & Japan & $115 / 115$ & ELISA kit & BioVender & $4.67 \pm 2.48$ & $3.33 \pm 1.88$ & 8 \\
\hline Wägsäter et al. [38] & Sweden & $35 / 34$ & ELISA kit & R\&D Systems & $2.62 \pm 0.70$ & $3.42 \pm 0.77$ & 7 \\
\hline Zhao et al. [39] & China & $358 / 286$ & ELISA kit & Biovision Inc & $8.03 \pm 4.99$ & $5.69 \pm 3.18$ & 8 \\
\hline Total & & $1199 / 1492$ & & & & & \\
\hline
\end{tabular}

NOS, Newcastle-Ottawa Scale

When we stratified the studies on CRC by the sample sources (serum and plasma), 9 studies offered relevant data for serum resistin level, and 7 studies offered relevant data for plasma resistin level, shown in Fig. 2. Subgroup analysis in CRC revealed that the serum resistin level was significantly higher in patients compared to controls $(\mathrm{MD}=4.61,95 \% \mathrm{CI}=2.32-6.91, p<0.0001)$, whereas a higher level of plasma resistin was also found in patients compared to controls $(\mathrm{MD}=0.34,95 \%$ $\mathrm{CI}=0.13-0.54, p=0.001)$. In CRC patients, the mean difference of resistin is higher in serum samples than in plasma samples (serum vs. plasma: $\mathrm{MD}=4.61$ vs. $\mathrm{MD}=0.34$ ).

Again, when the studies on $\mathrm{BC}$ studies were stratified by menopausal status, 5 studies offered relevant data for premenopausal women, and 9 studies offered relevant data for postmenopausal women, depicted in Fig. 3. The mean difference in resistin level found for premenopausal women was significantly higher compared to premenopausal controls $(\mathrm{MD}=7.82,95 \% \mathrm{CI}=7.46-8.19$, $p<0.00001$ ), and for postmenopausal women the level of resistin was also higher in comparison with postmenopausal controls $(\mathrm{MD}=0.37,95 \% \mathrm{CI}=0.21-0.54$, $p<0.00001)$. The mean difference of resistin is higher in premenopausal women than in postmenopausal women (premenopausal vs. postmenopausal: $\mathrm{MD}=7.82$ vs. $\mathrm{MD}=0.37)$. From the funnel plot analysis for detecting the association of resistin (Fig. 7), we did not find any notable asymmetry for $\mathrm{CRC}$ and $\mathrm{BC}$.

\section{Meta-analysis of RETN polymorphisms and link with CRC and $B C$}

Table 4 shows the association of RETN genetic polymorphisms with CRC and BC. Analysis of RETN rs1862513 polymorphism in CRC revealed that four genetic association models including codominant 1 (GC vs. CC), codominant 2 (GG vs. CC), dominant model (GG + GC vs. CC), and allele contrast (G vs. C) are associated with significantly enhanced risk of CRC (OR 1.24, 95\% CI 1.05-1.47, $p=0.010$; OR 1.31, 95\% CI 1.018-1.69, $p=0.036$; OR 1.25, 95\% CI 1.07-1.46, $p=0.005$; and OR 1.16, 95\% CI 1.03-1.30, $p=0.012$, respectively) (Fig. 4). Again, analysis of rs1862513 polymorphism in BC also showed significantly strong association in codominant 2 (GG vs. CC), codominant 3 (GG vs. GC), recessive (GG vs. GC $+\mathrm{CC}$ ), and allele (G vs. C) models (OR 1.51, 95\% CI 1.12-2.03, $p=0.007$; OR 1.51, 95\% CI 1.12-2.04, $p=0.007$; OR $1.51,95 \%$ CI $1.15-1.99, p=0.004$; and OR $1.21,95 \%$ CI 1.05-1.40, $p=0.008$, respectively) (Fig. 5). 
Table 2 Characteristics of the selected studies evaluating resistin level with breast cancer in the meta-analysis

\begin{tabular}{|c|c|c|c|c|c|c|c|c|c|}
\hline \multirow[t]{2}{*}{ Study ID } & \multirow[t]{2}{*}{ Country } & \multirow[t]{2}{*}{$\begin{array}{l}\text { Sample } \\
\text { source }\end{array}$} & \multirow[t]{2}{*}{ Sample type } & \multirow[t]{2}{*}{$\begin{array}{l}\text { Cases/ } \\
\text { controls }\end{array}$} & \multirow[t]{2}{*}{ Assay type } & \multirow[t]{2}{*}{ Kit provider } & \multicolumn{2}{|c|}{$\begin{array}{l}\text { Mean resistin level (ng/ } \\
\mathrm{ml}) \pm \mathrm{SD}\end{array}$} & \multirow[t]{2}{*}{ NOS score } \\
\hline & & & & & & & Cases & Controls & \\
\hline Ahmed [40] & Iraq & Serum & $\begin{array}{l}\text { Premenopau- } \\
\text { sal }\end{array}$ & $90 / 90$ & ELISA kit & $\begin{array}{l}\text { Bio-Rad Labo- } \\
\text { ratories }\end{array}$ & $18.32 \pm 2.4$ & $3.5 \pm 0.5$ & 7 \\
\hline $\begin{array}{l}\text { Alokail et al. } \\
\text { [41] }\end{array}$ & KSA & Serum & Both & $56 / 53$ & ELISA kit & $\begin{array}{l}\text { Immunodiag- } \\
\text { noztik }\end{array}$ & $18.9 \pm 1.2$ & $15.2 \pm 1$ & 7 \\
\hline Aly et al. [42] & KSA & Serum & UD & $35 / 40$ & ELISA kit & Invitrogen & $4.42 \pm 4.74$ & $1.84 \pm 2.35$ & 7 \\
\hline $\begin{array}{l}\text { Assiri \& Kamel } \\
\text { [43] }\end{array}$ & KSA & Serum & $\begin{array}{l}\text { Postmeno- } \\
\text { pausal }\end{array}$ & $110 / 89$ & ELISA kit & R\&D systems & $26.24 \pm 1.95$ & $22.63 \pm 3.99$ & 8 \\
\hline Assiri et al. [44] & $\mathrm{KSA}$ & Serum & Both & $82 / 68$ & ELISA kit & R\&D systems & $26.24 \pm 1.59$ & $22.69 \pm 2.58$ & 8 \\
\hline $\begin{array}{l}\text { Crisóstomo } \\
\text { et al. [45] }\end{array}$ & Portugal & Serum & Both & $77 / 77$ & ELISA kit & Duo Set ELISA & $14.58 \pm 10$ & $10.86 \pm 8.55$ & 8 \\
\hline $\begin{array}{l}\text { Dalamaga et al. } \\
\text { [46] }\end{array}$ & Greece & Serum & $\begin{array}{l}\text { Postmeno- } \\
\text { pausal }\end{array}$ & 102/102 & ELISA kit & Avibion & $11.2 \pm 6.4$ & $7.7 \pm 4.85$ & 8 \\
\hline $\begin{array}{l}\text { Dalamaga et al. } \\
\text { [47] }\end{array}$ & Greece & Serum & $\begin{array}{l}\text { Postmeno- } \\
\text { pausal }\end{array}$ & 103/103 & ELISA kit & Avibion & $11.24 \pm 6.44$ & $7.73 \pm 4.85$ & 8 \\
\hline $\begin{array}{l}\text { Georgiou et al. } \\
\text { [48] }\end{array}$ & Greece & Serum & Both & $157 / 52$ & ELISA kit & BioVendor & $6.09 \pm 3.08$ & $6.16 \pm 1.85$ & 7 \\
\hline $\begin{array}{l}\text { Gunter et al. } \\
\text { [49] }\end{array}$ & USA & Plasma & $\begin{array}{l}\text { Postmeno- } \\
\text { pausal }\end{array}$ & $875 / 821$ & ELISA kit & EMD Millipore & $12.1 \pm 1.8$ & $12.3 \pm 1.933$ & 38 \\
\hline Hou et al. [50] & China & Serum & Both & $80 / 50$ & ELISA kit & R\&D systems & $26.35 \pm 5.36$ & $23.32 \pm 4.75$ & 7 \\
\hline Kang et al. [51] & Korea & Plasma & Both & $41 / 43$ & ELISA kit & AdipoGen & $5.23 \pm 6.9$ & $1.46 \pm 2$ & 8 \\
\hline $\begin{array}{l}\text { Muñoz-Palom- } \\
\text { eque et al. [18] }\end{array}$ & Mexico & Serum & $\begin{array}{l}\text { Postmeno- } \\
\text { pausal }\end{array}$ & $20 / 40$ & ELISA kit & Preprotech Kit & $10.60 \pm 2.08$ & $8.26 \pm 2.38$ & 7 \\
\hline $\begin{array}{l}\text { Patrício et al. } \\
\text { [52] }\end{array}$ & Portugal & Serum & Both & $64 / 52$ & ELISA kit & Duo Set ELISA & $17.30 \pm 12.6$ & $11.60 \pm 11.4$ & 8 \\
\hline Wang et al. [53] & Taiwan & Serum & UD & $240 / 100$ & ELISA kit & eBioscience & $32.72 \pm 13.42$ & $27.36 \pm 5.49$ & 7 \\
\hline Total & & & & $2132 / 1780$ & & & & & \\
\hline
\end{tabular}

The meta-analysis of the RETN rs3745367 polymorphism in CRC and $\mathrm{BC}$, on the other hand, found no statistically significant link in any genetic model (Figs. 6, 7). Funnel plots for detecting the link of RETN rs1862513 and rs3745367 polymorphisms with CRC and BC are depicted in Fig. 8. However, no significant asymmetry was found.

\section{Publication bias, heterogeneity, and sensitivity analysis}

We also analyzed the publication bias for both CRC and $\mathrm{BC}$ with resistin level, as shown in Table 5 . In the case of CRC, Egger's $p$-value was found to be significant (0.044), but the Begg-Mazumdar $p$-value was statistically not significant $(0.280)$ for the overall sample (serum and plasma). However, no significant publication bias was found in subgroup analysis for serum and plasma resistin levels ( $p>0.05$ for both). Again, a significant publication bias was observed in overall BC samples (Egger's $p$-value: 0.0005 and Begg-Mazumdar $p$-value: 0.015), but in terms of premenopausal BC patients, neither Egger's test $(p=0.075)$ nor Begg-Mazumdar's test $(p=0.624)$ showed a statistically significant publication bias. However, for postmenopausal women, Egger's $p$-value was significant $(0.005)$ though the significance was not observed with Begg-Mazumdar $p$-value (0.532). We also found a significant heterogeneity $(p<0.00001)$ across the overall analysis of studies with resistin level in both CRC and BC as well as subgroup analysis according to the menopausal status of subjects (premenopausal and postmenopausal) in $\mathrm{BC}$ and sources of the sample (serum or plasma) in CRC (Figs. 2 and 3).

In terms of RETN polymorphisms with the risk of $\mathrm{CRC}$ and $\mathrm{BC}$, negligible publication bias was reported (Table 4). Begg-Mazumdar's $p$-value in the recessive model (0.039) and Egger's $p$-value in allele model (0.033) were significant in CRC and BC, respectively, for rs1862513 polymorphism. Only Egger's $p$-value in allele model (0.042) for rs3745367 was found to be significant. No other publication bias was found. Again, heterogeneity analysis showed that for rs1862513, only codominant model 3 (0.038) with CRC and for rs3745367 codominant 1 (0.029), dominant (0.041), and overdominant model 


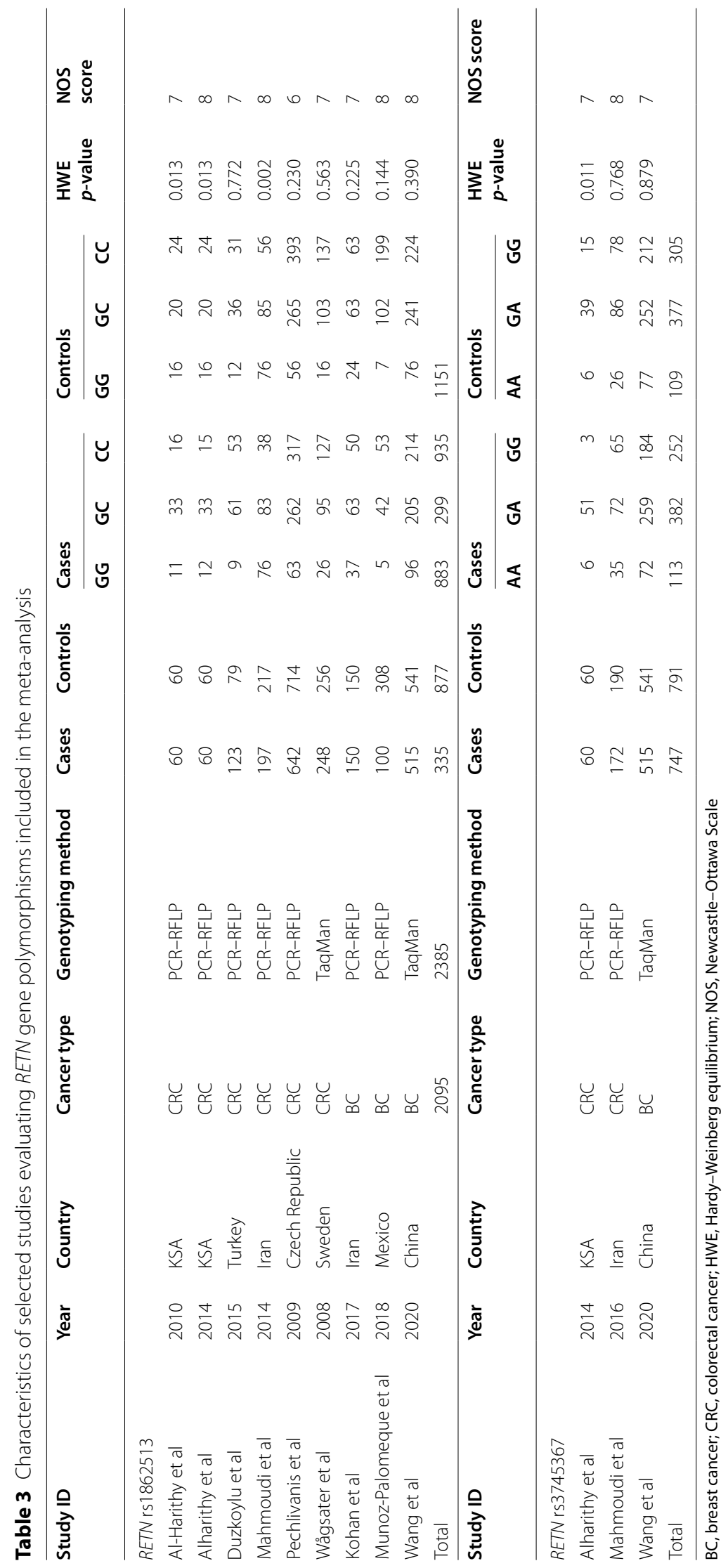




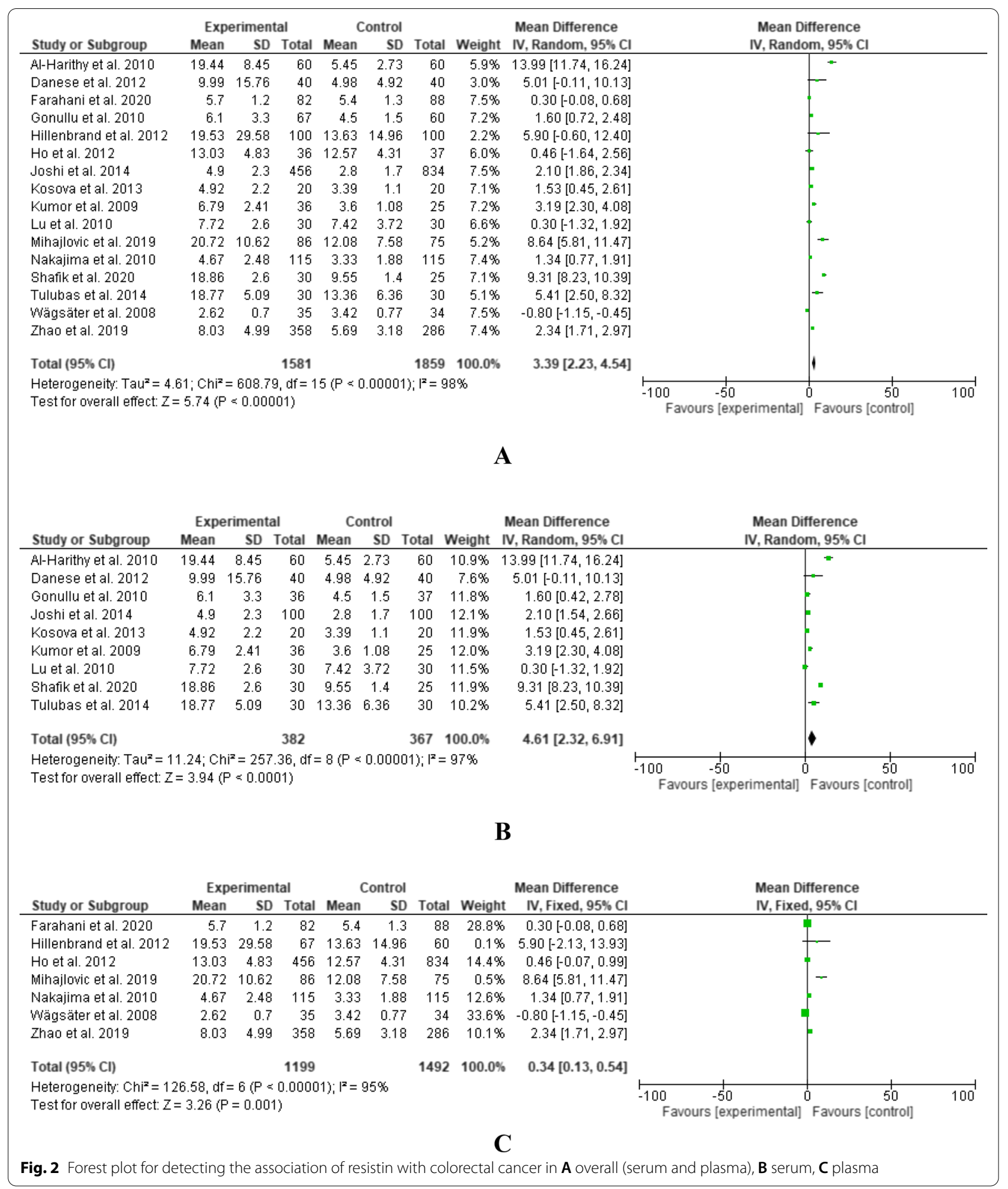

(0.041) showed significant heterogeneity (Table 4). Sensitivity analysis for detecting the link of RETN rs1862513 and rs3745367 polymorphisms with $\mathrm{CRC}$ and $\mathrm{BC}$ suggests the reliability and stability of our analysis, as shown in Additional file 1: Fig. S1. 


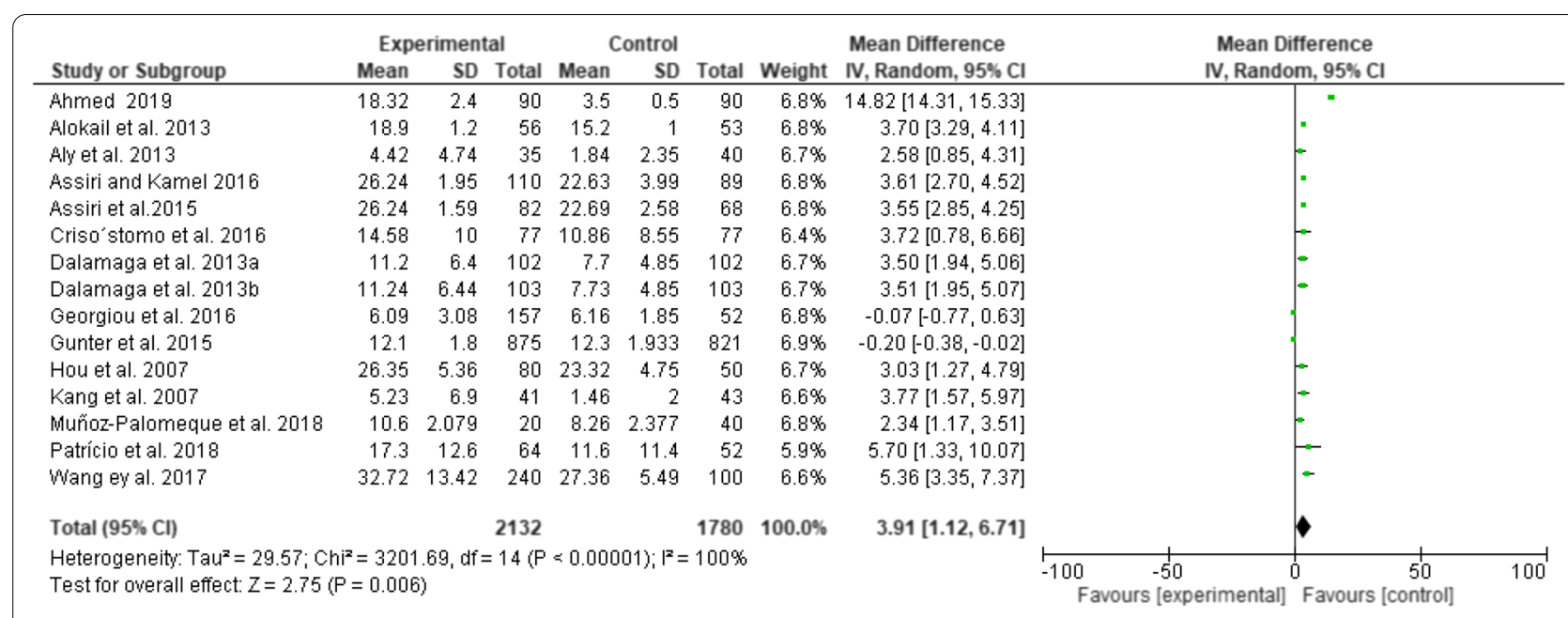

A

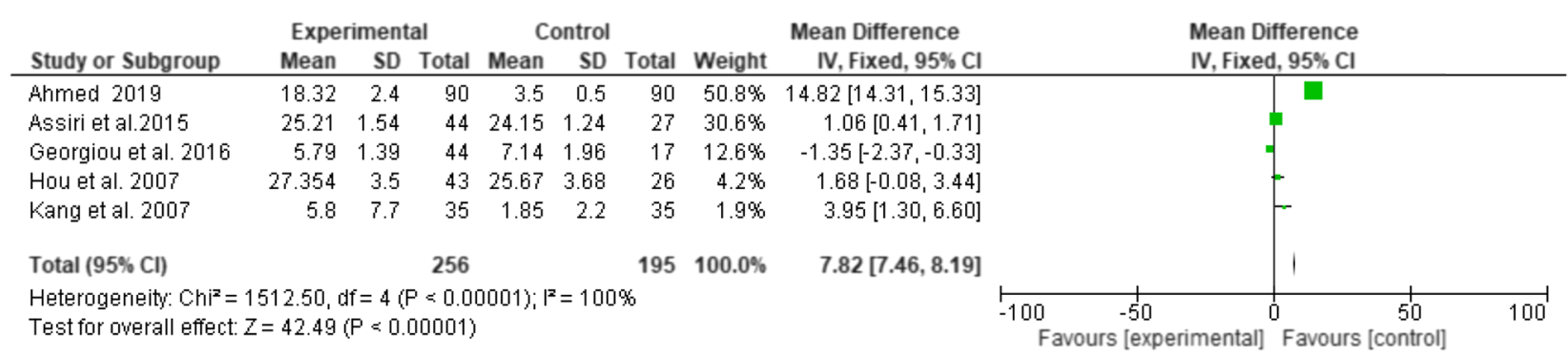

B

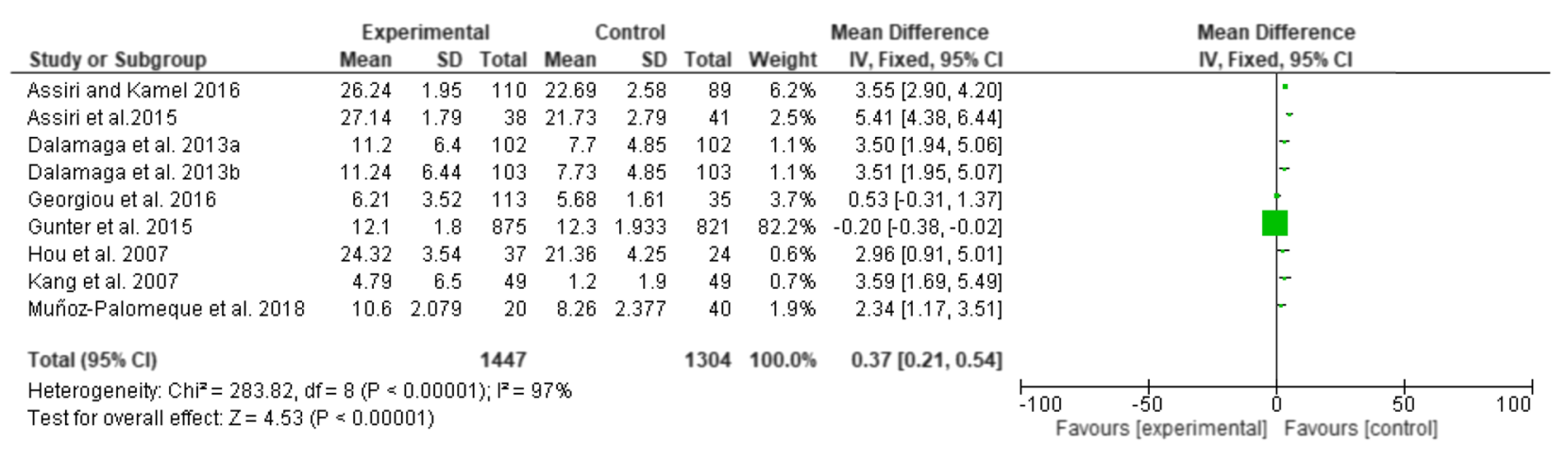

C

Fig. 3 Forest plot for detecting the association of resistin with breast cancer in $\mathbf{A}$ overall (premenopausal and postmenopausal), B premenopausal women, $\mathbf{C}$ postmenopausal women

\section{Discussion}

Resistin, an adipocytokine secreted by monocytes and macrophages, has been extensively studied due to its numerous roles in different physiological and pathological processes. It has been found that resistin is associated with inflammatory, metabolic, autoimmune processes in the human body as well as several cancers, including colorectal, breast, lung, endometrial, gastric, pancreatic, and liver cancers [53, 56, 57]. Again, RETN gene, which encodes resistin, has also been investigated for its role in 
Table 4 Meta-analysis and subgroup analysis of selected studies evaluating the association of RETN gene polymorphisms with colorectal and breast cancer

\begin{tabular}{|c|c|c|c|c|c|c|c|c|}
\hline \multirow[t]{2}{*}{ Genetic model } & \multicolumn{3}{|c|}{ Test of association } & \multicolumn{3}{|c|}{ Test of heterogeneity } & \multicolumn{2}{|c|}{ Publication bias ( $p$-value) } \\
\hline & OR & $95 \% \mathrm{Cl}$ & $p$-value & Model & $p$-value & $I^{2}(\%)$ & Egger's test & $\begin{array}{l}\text { Begg- } \\
\text { Mazumdar's } \\
\text { test }\end{array}$ \\
\hline \multicolumn{9}{|l|}{ RETN rs1862513 (CRC) } \\
\hline Codominant 1 (GC vs. CC) & 1.24 & $1.05-1.47$ & 0.010 & Fixed & 0.165 & 36.28 & 0.226 & 0.091 \\
\hline Codominant 2 (GG vs. CC) & 1.31 & $1.018-1.69$ & 0.036 & Fixed & 0.292 & 18.74 & 0.236 & 0.348 \\
\hline Codominant 3 (GG vs. GC) & 0.85 & $0.56-1.29$ & 0.444 & Random & 0.038 & 57.58 & 0.125 & 0.091 \\
\hline Dominant model (GG + GC vs. CC) & 1.25 & $1.07-1.46$ & 0.005 & Fixed & 0.418 & 0 & 0.526 & 0.188 \\
\hline Recessive model (GG vs. GC + CC) & 1.01 & $0.72-1.43$ & 0.934 & Random & 0.095 & 46.74 & 0.120 & 0.039 \\
\hline Over dominant (GC vs. GG + CC) & 1.25 & $0.98-1.60$ & 0.070 & Random & 0.097 & 46.37 & 0.168 & 0.060 \\
\hline Allele contrast (G vs. C) & 1.16 & $1.03-1.30$ & 0.012 & Fixed & 0.541 & 0 & 0.297 & 0.091 \\
\hline \multicolumn{9}{|l|}{ RETN rs 1862513 (BC) } \\
\hline Codominant 1 (GC vs. CC) & 1.05 & $0.86-1.30$ & 0.622 & Fixed & 0.101 & 56.43 & 0.244 & 0.602 \\
\hline Codominant 2 (GG vs. CC) & 1.51 & $1.12-2.03$ & 0.007 & Fixed & 0.360 & 2.23 & 0.166 & 0.117 \\
\hline Codominant 3 (GG vs. GC) & 1.51 & $1.12-2.04$ & 0.007 & Fixed & 0.969 & 0 & 0.074 & 0.117 \\
\hline Dominant model (GG + GC vs. CC) & 1.16 & $0.95-1.41$ & 0.135 & Fixed & 0.109 & 54.89 & 0.124 & 0.602 \\
\hline Recessive model (GG vs. GC + CC) & 1.51 & $1.15-1.99$ & 0.004 & Fixed & 0.653 & 0 & 0.125 & 0.117 \\
\hline Over dominant (GC vs. GG + CC) & 1.02 & $0.73-1.43$ & 0.912 & Random & 0.095 & 57.48 & 0.346 & 0.117 \\
\hline Allele contrast (G vs. C) & 1.21 & $1.05-1.40$ & 0.008 & Fixed & 0.172 & 43.23 & 0.033 & 0.117 \\
\hline \multicolumn{9}{|l|}{ RETN rs3745367 (CRC + BC) } \\
\hline Codominant 1 (AG vs. GG) & 1.41 & $0.80-2.48$ & 0.239 & Random & 0.029 & 71.64 & 0.436 & 0.602 \\
\hline Codominant 2 (AA vs. GG) & 1.27 & $0.93-1.74$ & 0.138 & Fixed & 0.142 & 48.71 & 0.117 & 0.117 \\
\hline Codominant 3 (AA vs. AG) & 1.04 & $0.77-1.40$ & 0.794 & Fixed & 0.245 & 28.99 & 0.890 & 0.602 \\
\hline Dominant model (AA + AG vs. GG) & 1.42 & $0.85-2.36$ & 0.182 & Random & 0.041 & 68.78 & 0.287 & 0.117 \\
\hline Recessive model (AA vs. AG + GG) & 1.12 & $0.84-1.49$ & 0.443 & Fixed & 0.324 & 11.32 & 0.786 & 0.602 \\
\hline Over dominant ( $A G$ vs. $A A+G G$ ) & 1.24 & $0.78-1.98$ & 0.359 & Random & 0.041 & 68.66 & 0.627 & 0.602 \\
\hline Allele contrast (A vs. G) & 1.14 & $0.98-1.31$ & 0.083 & Fixed & 0.397 & 0 & 0.042 & 0.117 \\
\hline
\end{tabular}

Bold values indicate statistically significant $(p<0.05)$

$\mathrm{BC}$, breast cancer; $\mathrm{CRC}$, colorectal cancer; $\mathrm{OR}$, odds ratio; $95 \% \mathrm{Cl}, 95 \%$ confidence interval

different diseases, including CRC and BC. Two common SNPs in RETN gene, namely, rs1862513 and rs3745367, have been evaluated for the risk link with BC and CRC $[18,21-23]$. This combined meta-analytic approach summarized that serum and plasma resistin levels are positively connected with an increased risk of CRC and BC. Again, RETN rs1862513 is also linked with the risk of CRC. Regardless of the inconsistent outcomes of the previous analyses, this is the first study evaluating the relationship of resistin levels and RETN gene polymorphisms at a time in both $B C$ and $C R C$ patients.

Accumulating evidence suggests that there is a significant correlation between attenuation in circulatory resistin levels and different diseases. It has been proposed that resistin plays a key role in cancer progression and cell cycle regulation. Resistin also has a potential link between inflammation, atherosclerosis, obesity, cardiovascular pathology, non-alcoholic fatty liver disease, and rheumatic diseases [34, 48]. Studies revealed that circulating resistin could promote several processes, including metastasis, proliferation, and angiogenesis associated with cancer development through stimulating different signaling mechanisms such as p38 MAPK/ NF-KB and PI3K/Akt pathways [58]. Although multiple studies with resistin found that higher resistin levels are linked to an increased risk of carcinogenesis, a few studies found no or an insignificant association.

The connection of resistin with CRC risk has been studied extensively in a wide variety of populations. The potential effect of resistin in CRC can be elucidated via different mechanisms. Several in vitro studies have demonstrated that the increased levels of resistin have proinflammatory effects controlled by the stimulation of TLR4 receptor and NF- $\mathrm{kB}$ signaling pathways. Besides, some studies also reported that resistin regulates matrix metalloproteinases (MMPs) production and modulates vascular endothelial growth factor (VEGF) secretion, which is linked with tumor invasiveness [4]. We found that high 


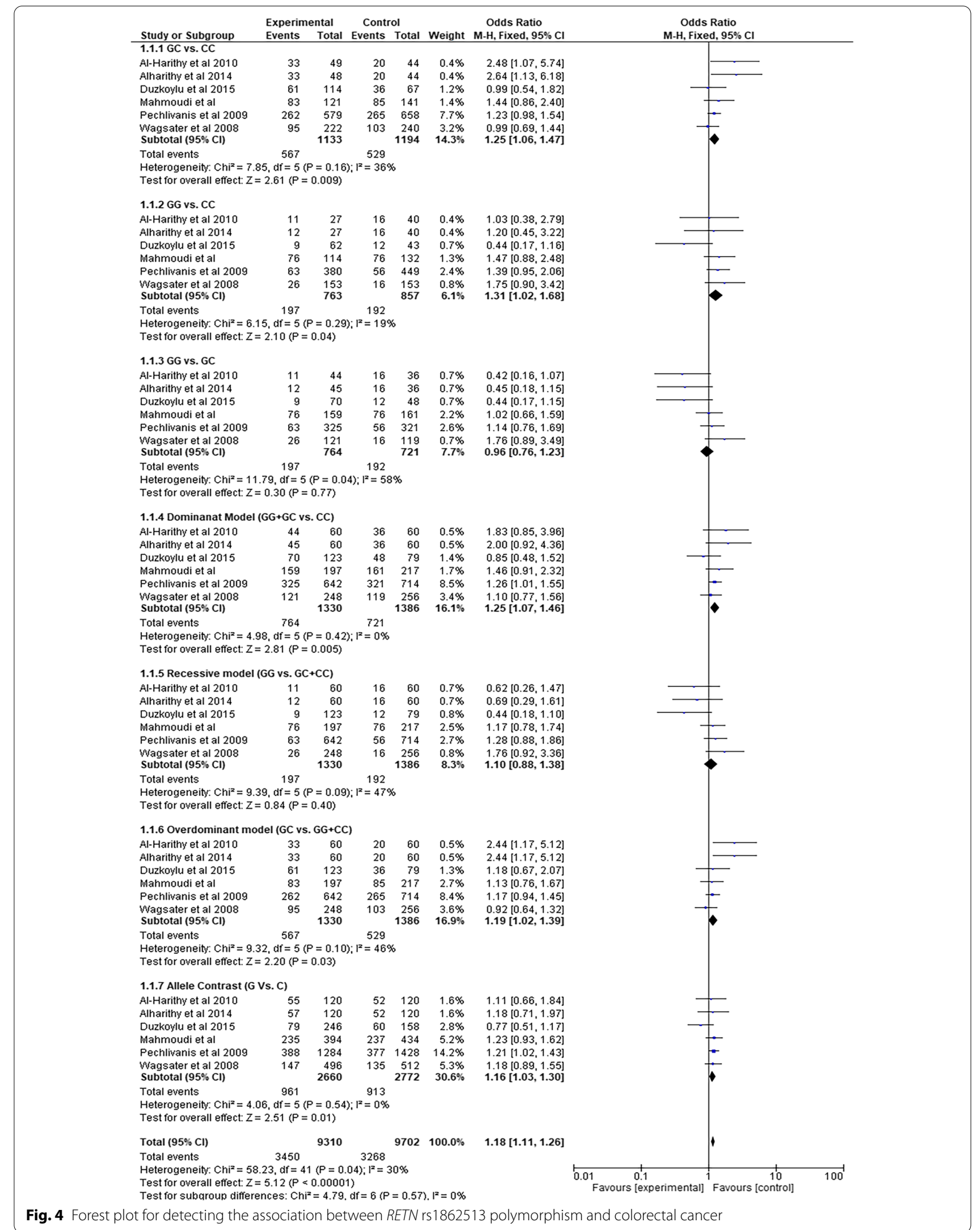




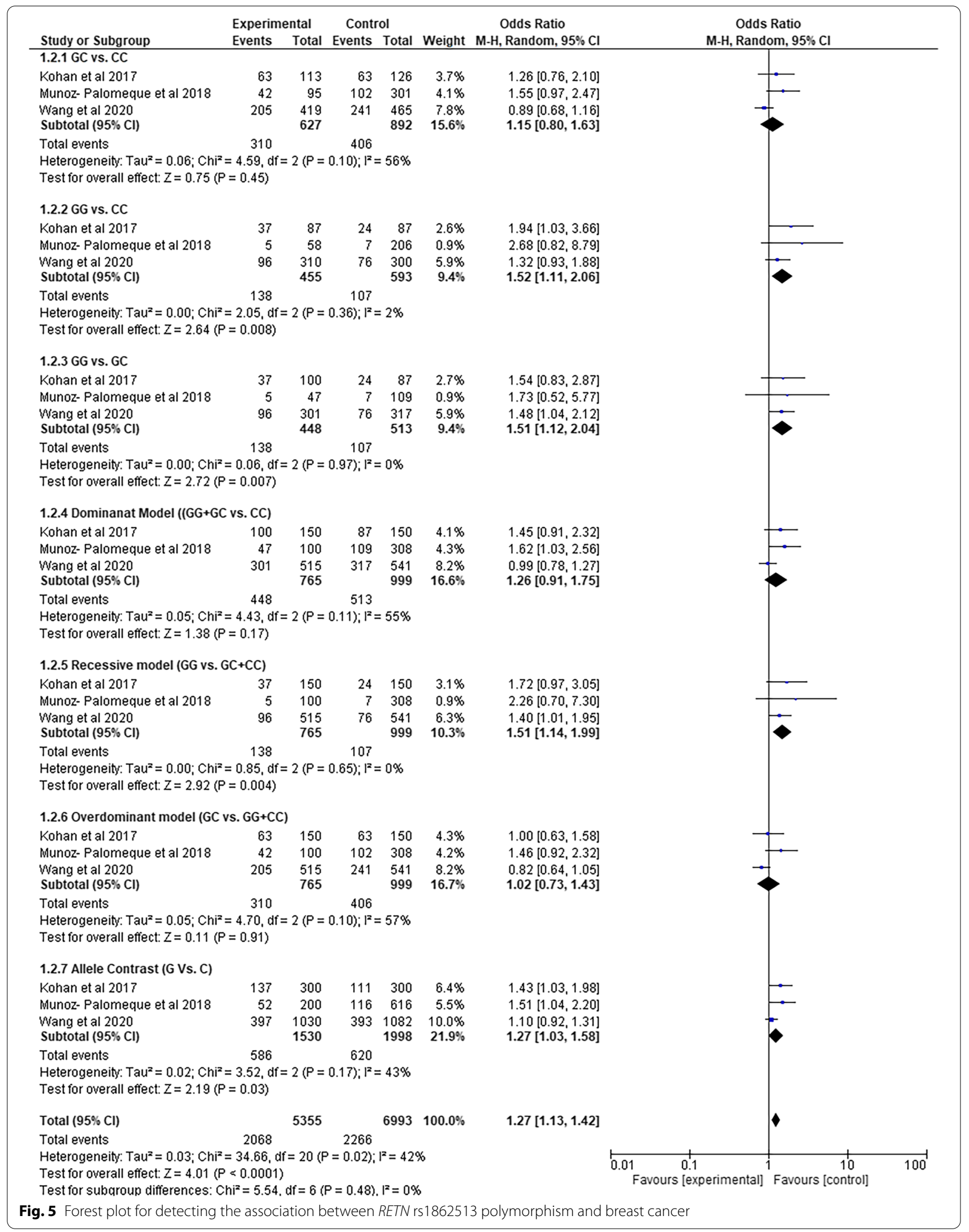




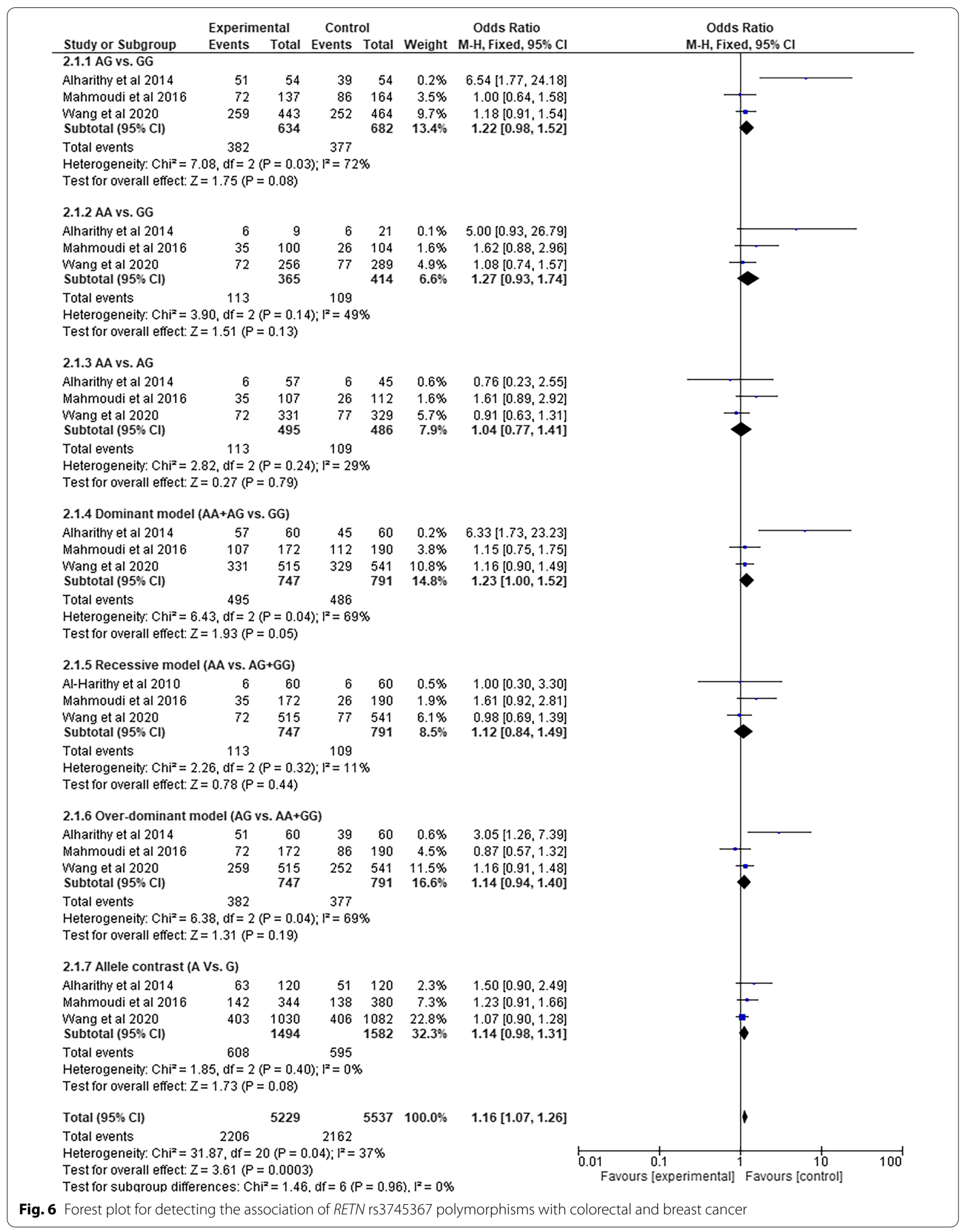




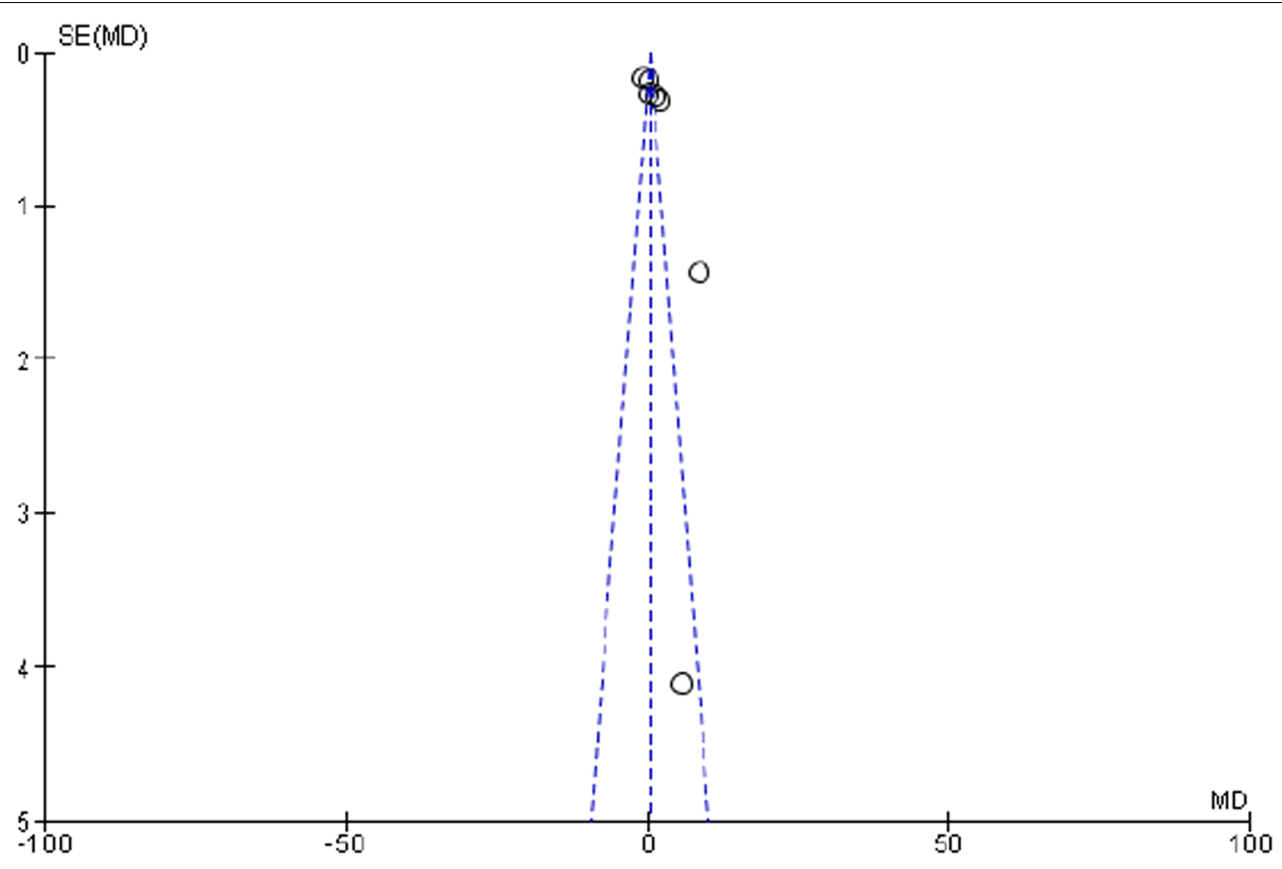

$\mathbf{A}$

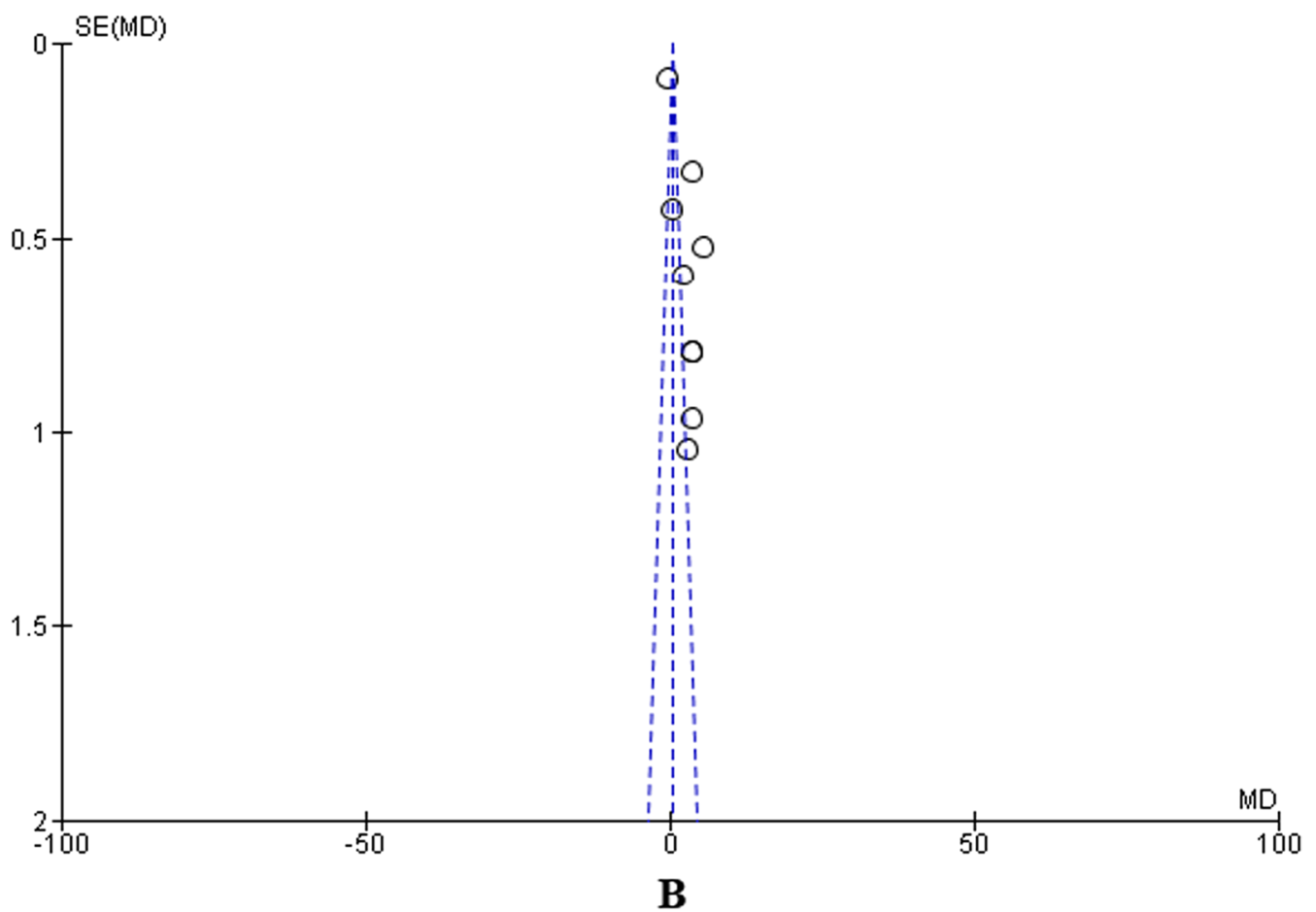

Fig. 7 Funnel plot for detecting the association of resistin in $\mathbf{A}$ colorectal cancer, $\mathbf{B}$ breast cancer

resistin levels are associated with CRC. According to our findings, patients with CRC have significantly higher resistin concentration than that of the control group $(\mathrm{MD}=3.39)$. Our analysis is consistent with the previous findings in different populations, including population from the Kingdom of Saudi Arabia [25], Italy [26], Turkey [27, 29, 33], South Korea [28], Poland [30], China [31, 39], 

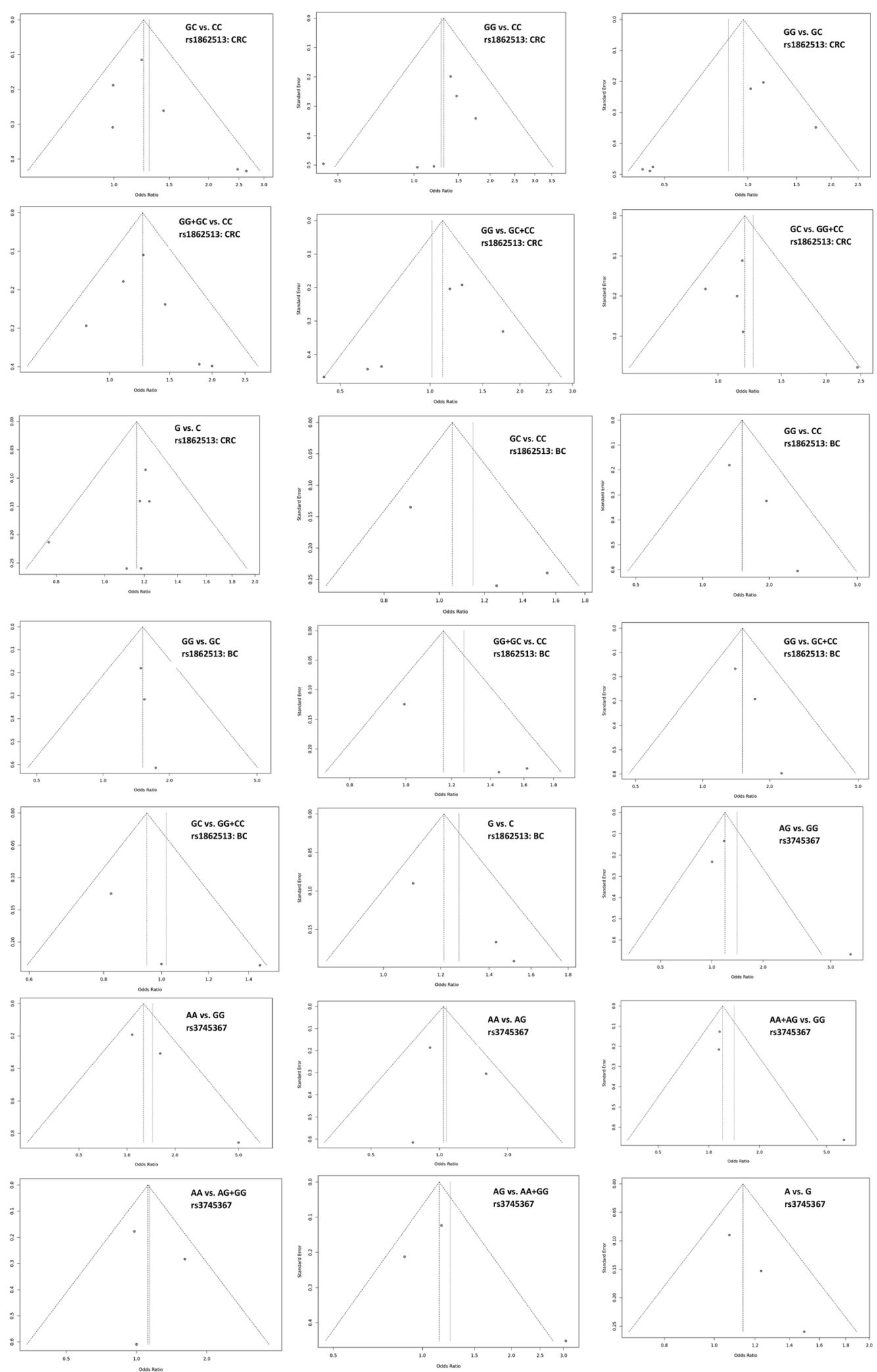

Fig. 8 Funnel plots for detecting the association of RETN rs 1862513 and rs3745367 polymorphisms with colorectal and breast cancer 
Table 5 Analysis of publication bias in selected studies evaluating resistin level with colorectal and breast cancer

\begin{tabular}{llll}
\hline Cancer type & Sample type & Egger's $\boldsymbol{p}$-value & $\begin{array}{l}\text { Begg- } \\
\text { Mazumdar's } \\
\boldsymbol{p} \text {-value }\end{array}$ \\
\hline Colorectal cancer & Overall & 0.044 & 0.280 \\
& Serum & 0.284 & 0.404 \\
& Plasma & 0.968 & 0.652 \\
Breast cancer & Overall & 0.0005 & 0.015 \\
& Premenopausal & 0.075 & 0.624 \\
& Postmenopausal & 0.005 & 0.532 \\
\hline
\end{tabular}

${ }^{*} p<0.05$ considered as statistically significant

Egypt [32], Iran [34], Germany [35], America [36], Serbia [11], and Japan [37].

Again, based on CRC subgroup analysis, we uncovered that serum resistin levels were significantly higher in CRC patients compared to controls $(\mathrm{MD}=4.61)$. Our findings are consistent with previous findings in Saudi Arabian [25], Italian [26], Turkish [27, 29, 33], South Korean [28], Polish [30], Chinese [31], and Egyptian [32] population. We found an elevated plasma resistin level in CRC patients compared to healthy controls $(\mathrm{MD}=0.34)$. Our results are in concordance with the previous findings reported in Iranian [34], German [35], American [36], Serbian [11], Japanese [37], and Chinese [39] populations. We also did not observe any notable asymmetry in the funnel plot for CRC. However, in terms of plasma resistin level, our findings are inconsistent with a casecontrol study in the Swedish population (35 cases and 34 controls) where Wägsäter et al. [38] reported a decreased plasma resistin level $(2.62 \pm 0.70 \mathrm{ng} / \mathrm{ml})$ in CRC patients in compared to the controls $(3.42 \pm 0.77 \mathrm{ng} / \mathrm{ml})$.

Elevated resistin levels in serum or plasma have been found to be correlated with an increased risk of $\mathrm{BC}$ [59]. A higher expression of resistin in $\mathrm{BC}$ tissues was also found to be significantly linked with the tumor size, tumor stage, estrogen receptor status, lymph node metastasis, and poor survival [60]. Previous studies have demonstrated that increased resistin expression in $\mathrm{BC}$ tissues is linked with cancer progression, premenopausal $\mathrm{BC}$, postmenopausal $\mathrm{BC}$, and poor prognosis of cancer [17]. Recent epidemiologic studies also correlated resistin levels with $\mathrm{BC}$ and proved that this association is not dependent on age, BMI, menopausal status, and other biomarkers such as glucose adiponectin levels in patients [44].

Our present meta-analysis reported that the levels of resistin in fifteen studies that included 2132 BC patients and 1780 controls, and the resistin level were significantly higher in $\mathrm{BC}$ patients $(\mathrm{MD}=3.91)$. Our findings are consistent with previous reports in different ethnicities, including Iraqi [40], Arabians [41-44], Portuguese [45, 52], Greek [46, 47], Chinese [50], Korean [51], Mexican [18], and Taiwanese [53] populations. However, two studies included in the analysis did not show consistency with our findings. A large case-control study in the USA with $875 \mathrm{BC}$ cases and 821 controls showed that the mean resistin level in patients was slightly lower $(12.1 \pm 1.8 \mathrm{ng} / \mathrm{ml})$ than that of the controls $(12.3 \pm 1.933 \mathrm{ng} / \mathrm{ml})$ [49]. Another case-control study in 157 cases of BC and 52 healthy controls from Greece reported the negative relationship between higher resistin level and $\mathrm{BC}$ risk. They found that the resistin level was $6.09 \pm 3.08 \mathrm{ng} / \mathrm{ml}$ in $\mathrm{BC}$ patients and $6.16 \pm 1.85 \mathrm{ng} / \mathrm{ml}$ in the control subjects, depicting a very low difference between the two groups [48].

Again, we found a substantially higher level of resistin in premenopausal and postmenopausal patients relative to controls when the studies on $\mathrm{BC}$ were stratified by menopausal status (premenopausal vs. postmenopausal: $M D=7.82$ vs. $M D=0.37$ ). Our findings are consistent with previous studies with premenopausal women [40, 44, 50, 51]. However, a study by Georgiou et al. [48] reported an inverse relationship where premenopausal patients had lower resistin levels than premenopausal controls. Our findings with postmenopausal women are consistent with our other studies [18, 43, 44, 46, 47, 50, 51]. However, one previous study by Gunter et al. [49] depicted inconsistency with our finding. From the funnel plot analysis for detecting the association of resistin, we did not find any significant asymmetry for the risk of BC.

The association of RETN polymorphisms with CRC and $\mathrm{BC}$ has been previously investigated in multiple populations. In our study, the meta-analysis of RETN gene rs1862513 polymorphism in CRC demonstrated that codominant 1 (OR 1.24), codominant 2 (OR 1.31), dominant (OR 1.25), and allele model (OR 1.16) are significantly connected with enhanced risk of CRC. Our results are in conformation with the previous results [19]. However, no association with CRC was observed in some previous studies [11, 21, 25, 38]. Again, rs1862513 polymorphism in $\mathrm{BC}$ also showed a significantly strong correlation in codominant 2 (OR 1.51), codominant 3 (OR 1.51), recessive (OR 1.51), and allele (OR 1.21) models. Muñoz-Palomeque et al. [18] also showed a significantly increased risk of BC with this SNP. However, no statistically strong correlation was observed in previous analysis by Wang et al. [22].

The meta-analysis of the RETN rs3745367 polymorphism in CRC and BC, on the other hand, found no statistically significant risk association in any genetic model. Our results are consistent with those of Wang et al. [22] in BC, Mahmoudi et al. [23] in CRC. However, Alharithy 
et al. [24] showed a significantly increased association of rs3745367 variant with the risk of CRC.

We should point out some limitations of our metaanalysis. Firstly, although we have followed a perfect strategy for literature search, there might be a possibility of missing some eligible studies. Furthermore, we only included studies that were published in English. Secondly, there appeared some sort of publication bias. Thirdly, we found significant heterogeneity across the studies. Study design, quality, and sample type may account for this heterogeneity. Fourthly, present meta-analyses are based on case-control studies, and the inherent lacking's of which may influence our outcomes to some extent. Finally, we could not discuss some potential confounders that may be associated with the alteration of resistin levels and RETN polymorphisms such as obesity, smoking, dietary habits, sex, alcohol, lack of exercise, and clinicopathological characteristics, including tumor stage, distant metastasis, and type of cancers. However, keeping in mind the potential role of circulating resistin and RETN genetic polymorphisms in both CRC and $\mathrm{BC}$ risk and the inconsistent published evidence based on the effect of resistin, the present study is the first combined effort with both cancers and is of greater importance.

\section{Conclusion}

In conclusion, the present study indicates that serum and plasma resistin levels are positively associated with an elevated risk of CRC. Besides, elevated resistin level is positively associated with increased $\mathrm{BC}$ risk in premenopausal and postmenopausal women. Moreover, RETN rs1862513 polymorphism is connected with the risk of both CRC and BC. Our analysis will help enhance the understanding of cancer risks with resistin levels and RETN genetic variants. However, based on the limitations mentioned above, more randomized trials with a larger sample size are required to confirm the relationship of resistin and RETN polymorphisms with the development of CRC and BC.

\section{Methods}

\section{Literature search}

Both meta-analyses were carried out following the guidelines of PRISMA [61]. For collecting data of resistin, a comprehensive literature search was conducted in PubMed, ScienceDirect, BMC, EMBASE, Cochrane Library, Web of Science, and Google Scholar databases using the following search keywords: "resistin," "adipokines," "adipocytokines," "serum resistin," "plasma resistin," "resistin and colorectal cancer," "resistin and breast cancer." Again, for RETN genetic polymorphisms-related data, we searched on the same databases using the following keywords: "resistin," "RETN," "SNPs," "polymorphisms," “variants," "rs1862513," or “C-180G," or “C-420G," "rs3745367," or "G+299A," "RETN and colorectal cancer," "RETN and breast cancer." In addition, we manually reviewed the list of bibliography from the retrieved articles to include relevant studies. Furthermore, we have added literature only written in English.

\section{Study selection criteria}

The following criteria were used to select studies for inclusion in both meta-analyses: (1) If the study evaluated the link of resistin level and RETN polymorphisms (rs1862513 and/or 3745367) with BC and CRC; (2) if it was a case-control, cross-sectional, or cohort study; (3) if the study provided appropriate data to calculate resistin level and in case of genetic meta-analysis if the studies provided useful genotypic data; and (4) if the study performed on human. Studies were excluded if they had the following criteria: (1) If the study was a review, editorial, or letter to the editor; (2) if there is no control cohort; (3) if the study had inadequate data; and (4) if the authors with incomplete study data did not reply to the requests from the authors.

\section{Data extraction}

Two authors (MAA and TA) independently assessed the eligibility of included studies and any disagreements were resolved by consensus with another author (MSI). From each article selected, we retrieved the following information: first author's name, publication year, study conducting country, cancer type, sources of the sample (plasma or serum) or SNP studied, type of sample, number of study cases and controls, assay type or genotyping method, name of the kit provider, mean resistin level (ng/ $\mathrm{ml}) \pm$ standard deviation (SD) in both cases and controls, and p-value of HWE of controls for genetic association study. Where median and range or interquartile range were given for resistin level, we calculated mean and SD using the method described by Wan et al. [62].

\section{Quality score assessment}

The quality of each selected study for our meta-analyses involving the correlation of serum or plasma resistin levels or the association of RETN polymorphisms in CRC and BC was assessed based on the Newcastle-Ottawa Scale (NOS) [63]. We evaluated the quality of each study following three aspects: (1) the study selection procedure, (2) literature comparability, and (3) the exposure determination in case-control studies. NOS total scores ranged from 0 to 9 , with a score greater than 7 indicating a high-quality study. 


\section{Statistical analysis}

All statistical analysis was performed using the Review Manager (RevMan) 5.4 software (Nordic Cochrane Center, Copenhagen, Denmark). We calculated all data as mean $(\mathrm{ng} / \mathrm{ml}) \pm \mathrm{SD}$ to assess plasma or serum resistin relationship with CRC and BC. Again, for genetic association analysis, we calculated the association of RETN variants in seven genetic models, including codominant 1-3, dominant, overdominant, recessive, and allele model. The Q-statistic to test the heterogeneity between studies and the $I^{2}$-statistic to quantify the total differences resulting from heterogeneity was calculated. We selected the random effect model for calculating the pooled mean differences when $p<50 \%$. Our meta-analyses also assessed potential publication bias by applying Egger's regression test [64] and Begg's rank correlation test [65]. We stratified all collected data according to the menopausal status of subjects (premenopausal and postmenopausal) in $\mathrm{BC}$ and sources of the sample (serum or plasma) in CRC and employed in subgroup analyses (forest plot) to evaluate the source of heterogeneity for evaluating the association of resistin level. In all analyses, $p<0.05$ was considered to be statistically significant.

\begin{abstract}
Abbreviations
95\% Cl: 95\% Confidence interval; BC: Breast cancer; BMI: Body mass index; CRC : Colorectal cancer; HWE: Hardy-Weinberg equilibrium; MD: Mean difference; MMP: Matrix metalloproteinase; NOS: Newcastle-Ottawa Scale; OR: Odds ratio; PRISMA: Preferred reporting items for systematic reviews and meta-analyses; RELM: Resistin-like molecule; RETN: Resistin; SNP: Single nucleotide polymorphism; VEGF: Vascular endothelial growth factor.
\end{abstract}

\section{Supplementary Information}

The online version contains supplementary material available at https://doi. org/10.1186/s43042-022-00240-w.

Additional file 1. Supplementary material: Sensitivity analysis.

\section{Acknowledgements}

The authors are grateful to the Department of Pharmacy and Laboratory of Pharmacogenomics and Molecular Biology, Noakhali Science and Technology University, Noakhali-3814, Bangladesh.

\section{Authors' contributions}

MSI analyzed the data, developed the software and conceptualized the study, validated the data analysis, supervised the study, wrote the review and edited; MAA and TA helped in literature search; MAA wrote the original draft and helped in methodology; MSS was involved in analysis, writing — reviewing and editing. All authors have read and approved the final manuscript.

\section{Funding}

Not applicable.

\section{Availability of data and materials}

The datasets used and/or analyzed during the current study are available from the corresponding author on reasonable request.

\section{Declarations}

Ethics approval and consent to participate

Not applicable.

\section{Consent for publication}

Not applicable.

\section{Competing interests}

The authors declare that they have no competing interests.

\section{Author details}

${ }^{1}$ Department of Pharmacy, Faculty of Science, Noakhali Science and Technology University, Sonapur 3814, Noakhali, Bangladesh. ${ }^{2}$ Laboratory of Pharmacogenomics and Molecular Biology, Department of Pharmacy, Noakhali Science and Technology University, Sonapur 3814, Noakhali, Bangladesh.

Received: 9 June 2021 Accepted: 17 September 2021

Published online: 01 March 2022

\section{References}

1. Wang CQ, Wang Y, Huang BF, Tang CH, Du Z, Zeng Y et al (2020) High expression of both resistin and fascin-1 predicts a poor prognosis in patients with colorectal cancer. Biomed Res Int 2020:8753175. https://doi. org/10.1155/2020/8753175

2. Karmokar PF, Shabnaz S, Aziz MA, Asaduzzaman M, Shahriar M, Bhuiyan MA et al (2020) Variants of SMAD1 gene increase the risk of colorectal cancer in the Bangladeshi population. Tumour Biol 42:1010428320958955. https://doi.org/10.1177/1010428320958955

3. Uyar GO, Sanlier N (2019) Association of adipokines and insulin, which have a role in obesity, with colorectal cancer. Eurasian J Med 51:191-195. https://doi.org/10.5152/eurasianjmed.2018.18089

4. Yang G, Fan W, Luo B, Xu Z, Wang P, Tang S et al (2016) Circulating resistin levels and risk of colorectal cancer: a meta-analysis. Biomed Res Int 2016:7367485. https://doi.org/10.1155/2016/7367485

5. Jafrin S, Aziz MA, Anonna SN, Akter T, Naznin NE, Reza S et al (2020) Association of TP53 codon 72 Arg >Pro polymorphism with breast and lung cancer risk in the South Asian population: A meta-analysis. Asian Pac J Cancer Prev 21:1511-1519. https://doi.org/10.31557/APJCP.2020.21.6. 1511

6. Ahmad A (2019) Breast cancer statistics: recent trends. Adv Exp Med Biol 1152:1-7. https://doi.org/10.1007/978-3-030-20301-6_1

7. Balkhi S, Mashayekhi F, Salehzadeh A, Saedi HS (2020) Matrix metalloproteinase (MMP)-1 and MMP-3 gene variations affect MMP-1 and -3 serum concentration and associates with breast cancer. Mol Biol Rep 47:9637-9644. https://doi.org/10.1007/s11033-020-05962-x

8. Coughlin SS (2019) Epidemiology of breast cancer in women. Adv Exp Med Biol 1152:9-29. https://doi.org/10.1007/978-3-030-20301-6_2

9. Chen SS, Tang CH, Chie MJ, Tsai CH, Fong YC, Lu YC et al (2019) Resistin facilitates VEGF-A-dependent angiogenesis by inhibiting miR-16-5p in human chondrosarcoma cells. Cell Death Dis 10:31. https://doi.org/10. 1038/s41419-018-1241-2

10. Zhou L, Li JY, He PP, Yu XH, Tang CK (2021) Resistin: potential biomarker and therapeutic target in atherosclerosis. Clin Chim Acta 512:84-91. https://doi.org/10.1016/j.cca.2020.11.010

11. Mihajlovic M, Ninic A, Sopic M, Miljkovic M, Stefanovic A, Vekic J et al (2019) Association among resistin, adenylate cyclase-associated protein 1 and high-density lipoprotein cholesterol in patients with colorectal cancer: a multi-marker approach, as a hallmark of innovative predictive, preventive, and personalized medicine. EPMA J 10:307-316. https://doi. org/10.1007/s13167-019-00178-x

12. Ghaemmaghami S, Mohaddes SM, Hedayati M, Gorgian Mohammadi M, Dehbashi G (2013) Resistin and visfatin expression in HCT-116 colorectal cancer cell line. Int J Mol Cell Med 2:143-150 
13. Tsai HC, Cheng SP, Han CK, Huang YL, Wang SW, Lee JJ et al (2019) Resistin enhances angiogenesis in osteosarcoma via the MAPK signaling pathway. Aging 11:9767-9777. https://doi.org/10.18632/aging.102423

14. Liu LY, Wang M, Ma ZB, Yu LX, Zhang Q, Gao AZ et al (2013) The role of adiponectin in breast cancer: a meta-analysis. PLoS ONE 8:e73183. https://doi.org/10.1371/journal.pone.0073183

15. Sudan SK, Deshmukh SK, Poosarla T, Holliday NP, Dyess DL, Singh AP et al (2020) Resistin: an inflammatory cytokine with multi-faceted roles in cancer. Biochim Biophys Acta Rev Cancer 1874:188419. https://doi. org/10.1016/j.bbcan.2020.188419

16. Qiu L, Zhang GF, Yu L, Wang HY, Jia XJ, Wang TJ (2018) Novel oncogenic and chemoresistance-inducing functions of resistin in ovarian cancer cells require miRNAs-mediated induction of epithelial-tomesenchymal transition. Sci Rep 8:12522. https://doi.org/10.1038/ s41598-018-30978-6

17. Lee JO, Kim N, Lee HJ, Lee YW, Kim SJ, Park SH et al (2016) Resistin, a fat-derived secretory factor, promotes metastasis of MDA-MB-231 human breast cancer cells through ERM activation. Sci Rep 6:18923. https://doi.org/10.1038/srep18923

18. Muñoz-Palomeque A, Guerrero-Ramirez MA, Rubio-Chavez LA, RosalesGomez RC, Lopez-Cardona MG, Barajas-Avilaet VH et al (2018) Association of RETN and CAP1 SNPs, expression and serum resistin levels with breast cancer in Mexican women. Genet Test Mol Biomark 22:209-217. https://doi.org/10.1089/gtmb.2017.0212

19. Pechlivanis S, Bermejo JL, Pardini B, Naccarati A, Vodickova L, Novotny J et al (2009) Genetic variation in adipokine genes and risk of colorectal cancer. Eur J Endocrinol 160:933-940. https://doi.org/10.1530/ EJE-09-0039

20. Hashemi M, Bahari G, Tabasi F, Moazeni-Roodi A, Ghavami S (2018) Association between rs1862513 and rs3745367 genetic polymorphisms of resistin and risk of cancer: a meta-analysis. Asian Pac J Cancer Prev 19:2709-2716. https://doi.org/10.22034/APJCP.2018.19.10. 2709

21. Mahmoudi T, Karimi K, Arkani M, Farahani H, Vahedi M, Dabiri R et al (2014) Resistin -420C>G promoter variant and colorectal cancer risk. Int J Biol Mark 29:e233-e238. https://doi.org/10.5301/jbm.5000079

22. Wang CQ, Tang $\mathrm{CH}$, Tzeng HE, Jin L, Zhao J, Kang L et al (2020) Impacts of RETN genetic polymorphism on breast cancer development. J Cancer 11:2769-2777. https://doi.org/10.7150/jca.38088

23. Mahmoudi T, Majidzadeh-A K, Karimi K, Farahani H, Dabiri R, Nobakht $\mathrm{H}$ et al (2016) Gly972Arg variant of insulin receptor substrate 1 gene and colorectal cancer risk in overweight/obese subjects. Int J Biol Mark 31:e68-e72. https://doi.org/10.5301/jbm.5000159

24. Alharithy RN (2014) Polymorphisms in RETN gene and susceptibility to colon cancer in Saudi patients. Ann Saudi Med 34:334-339. https://doi. org/10.5144/0256-4947.2014.334

25. Al-Harithy RN, Al-Ghafari AB (2010) Resistin in human colon cancer. Increased expression independently of resistin promoter C-180G genotype. Saudi Med J 31:495-500

26. Danese E, Montagnana M, Minicozzi AM, Bonafini S, Ruzzenente O, Gelati $M$ et al (2012) The role of resistin in colorectal cancer. Clin Chim Acta 413:760-764. https://doi.org/10.1016/j.cca.2012.01.019

27. Gonullu G, Kahraman H, Bedir A, Bektas A, Yücel I (2010) Association between adiponectin, resistin, insulin resistance, and colorectal tumors. Int J Colorectal Dis 25:205-212. https://doi.org/10.1007/ s00384-009-0828-6

28. Joshi RK, Kim WJ, Lee SA (2014) Association between obesity-related adipokines and colorectal cancer: a case-control study and meta-analysis. World J Gastroenterol 20:7941-7949. https://doi.org/10.3748/wjg.v20.i24. 7941

29. Kosova F, Coskun T, Kaya Y, Kara E, Ari Z (2013) Adipocytokine levels of colon cancer patients before and after treatment. Bratisl Lek Listy 114:394-397. https://doi.org/10.4149/bll_2013_083

30. Kumor A, Daniel P, Pietruczuk M, Małecka-Panas E (2009) Serum leptin adiponectin, and resistin concentration in colorectal adenoma and carcinoma (CC) patients. Int J Colorectal Dis 24:275-281. https://doi.org/ 10.1007/s00384-008-0605-y

31. Lu L, Yi L, Qiling M, Peizhen H (2010) Study on serum leptin, adiponectin and resistin concentration in patients with colorectal cancer. J Med Res 39:78-80
32. Shafik E, Mohareb DA, Hetta H, Khallaf S, Abdel-Rady N, Gaber Z et al (2020) Adipocytokine, leptin and resistin in combination with quantitative visceral adiposity as predictors of colorectal neoplasm: a case control study. IJCBR 4:121-131. https://doi.org/10.21608/JCBR.2020.28094.1029

33. Tulubas F, Mete R, Oznur M, Topcu B (2014) The role of adipocytokines in colon cancer and adenomas. J Med Biochem 33:135-142. https://doi.org/ 10.2478/jomb-2015-0001

34. Farahani $H$, Mahmoudi T, Asadi A, Nobakht H, Dabiri R, Hamta A (2020) Insulin resistance and colorectal cancer risk: the role of elevated plasma resistin levels. J Gastrointest Cancer 51:478-483. https://doi.org/10.1007/ s12029-019-00260-7

35. Hillenbrand A, Fassler J, Huber N, Xu P, Henne-Bruns D, Templin M et al (2012) Changed adipocytokine concentrations in colorectal tumor patients and morbidly obese patients compared to healthy controls. BMC Cancer 12:545. https://doi.org/10.1186/1471-2407-12-545

36. Ho GY, Wang T, Gunter MJ, Strickler HD, Cushman M, Kaplan RC et al (2012) Adipokines linking obesity with colorectal cancer risk in postmenopausal women. Cancer Res 72:3029-3037. https://doi.org/10.1158/ 0008-5472.CAN-11-2771

37. Nakajima TE, Yamada Y, Hamano T, Furuta K, Matsuda T, Fujita S et al (2010) Adipocytokines as new promising markers of colorectal tumors: adiponectin for colorectal adenoma, and resistin and visfatin for colorectal cancer. Cancer Sci 101:1286-1291. https://doi.org/10.1111/j.13497006.2010.01518.x

38. Wågsäter D, Mumtaz M, Löfgren S, Hugander A, Dimberg J (2008) Resistin in human colorectal cancer: increased expression independently of resistin promoter -420C > G genotype. Cancer Invest 26:1008-1014. https:// doi.org/10.1080/07357900802087267

39. Zhao X, Zhang Y, Deng L, Wang Y, Li Y, Chen M (2019) The association between Chinese patients' elevated omentin-1 levels, their clinicopathological features, and the risk of colorectal cancer. Int J Clin Exp Pathol 12:2264-2274

40. Ahmed HS (2020) Obesity and breast cancer: circulating adipokines and their potential diagnostic as risk biomarkers. Int J Res Pharm Sci 11:3061-3068. https://doi.org/10.26452/ijrps.v11i3.2408

41. Alokail MS, Al-Daghri N, Abdulkareem A, Draz HM, Yakout SM, Alnaami AM et al (2013) Metabolic syndrome biomarkers and early breast cancer in Saudi women: evidence for the presence of a systemic stress response and/or a pre-existing metabolic syndrome-related neoplasia risk? BMC Cancer 13:54. https://doi.org/10.1186/1471-2407-13-54

42. Aly R, Zalam S, Sharaf F (2013) Correlation between adiponectin and breast cancer. Life Sci J 10:313-331

43. Assiri AM, Kamel HF (2016) Evaluation of diagnostic and predictive value of serum adipokines: leptin, resistin and visfatin in postmenopausal breast cancer. Obes Res Clin Pract 10:442-453. https://doi.org/10.1016/j. orcp.2015.08.017

44. Assiri AM, Kamel HF, Hassanien MF (2015) Resistin, visfatin, adiponectin, and leptin: risk of breast cancer in pre- and postmenopausal saudi females and their possible diagnostic and predictive implications as novel biomarkers. Dis Mark 2015:253519. https://doi.org/10.1155/2015/ 253519

45. Crisóstomo J, Matafome P, Santos-Silva D, Gomes AL, Gomes M, Patrício M et al (2016) Hyperresistinemia and metabolic dysregulation: a risky crosstalk in obese breast cancer. Endocrine 53:433-442. https://doi.org/ 10.1007/s12020-016-0893-x

46. Dalamaga M, Karmaniolas K, Papadavid E, Pelekanos N, Sotiropoulos G, Lekka A (2013) Hyperresistinemia is associated with postmenopausal breast cancer. Menopause 20:845-851. https://doi.org/10.1097/GME. Ob013e31827f06dc

47. Dalamaga M, Sotiropoulos G, Karmaniolas K, Pelekanos N, Papadavid E, Lekka A (2013) Serum resistin: a biomarker of breast cancer in postmenopausal women? Association with clinicopathological characteristics, tumor markers, inflammatory and metabolic parameters. Clin Biochem 46:584-590. https://doi.org/10.1016/j.clinbiochem.2013.01.001

48. Georgiou GP, Provatopoulou X, Kalogera E, Siasos G, Menenakos E, Zografos GC et al (2016) Serum resistin is inversely related to breast cancer risk in premenopausal women. Breast 29:163-169. https://doi.org/10.1016/j. breast.2016.07.025

49. Gunter MJ, Wang T, Cushman M, Xue X, Wassertheil-Smoller S, Strickler $\mathrm{HD}$ et al (2015) Circulating adipokines and inflammatory markers and 
postmenopausal breast cancer risk. J Natl Cancer Inst 107:169. https://doi. org/10.1093/jnci/djv169

50. Hou WK, Xu YX, Yu T, Zhang L, Zhang WW, Fu CL et al (2007) Adipocytokines and breast cancer risk. Chin Med J 120:1592-1596

51. Kang JH, Yu BY, Youn DS (2007) Relationship of serum adiponectin and resistin levels with breast cancer risk. J Korean Med Sci 22:117-121. https://doi.org/10.3346/jkms.2007.22.1.117

52. Patrício M, Pereira J, Crisóstomo J, Matafome P, Gomes M, Seiça R et al (2018) Using resistin, glucose, age and BMl to predict the presence of breast cancer. BMC Cancer 18:29. https://doi.org/10.1186/ s12885-017-3877-1

53. Wang CH, Wang PJ, Hsieh YC, Lo S, Lee YC, Chen YC et al (2018) Resistin facilitates breast cancer progression via TLR4-mediated induction of mesenchymal phenotypes and stemness properties. Oncogene 37:589-600. https://doi.org/10.1038/onc.2017.357

54. Düzköylü Y, Arıkan S, Turan S, Yaylım I, Doğan MB, Sarı S et al (2015) Possible relationship between the resistin gene C-420G polymorphism and colorectal cancer in a Turkish population. Turk J Gastroenterol 26:392396. https://doi.org/10.5152/tjg.2015.0188

55. Kohan L (2017) Investigating the association of rs 1862513 genetic variant in resistin gene with susceptibility to breast cancer. J Fasa Univ Med Sci 7:217-222

56. Christodoulatos GS, Spyrou N, Kadillari J, Psallida S, Dalamaga M (2019) The role of adipokines in breast cancer: current evidence and perspectives. Curr Obes Rep 8:413-433. https://doi.org/10.1007/ s13679-019-00364-y

57. Gui Y, Pan Q, Chen X, Xu S, Luo X, Chen L (2017) The association between obesity related adipokines and risk of breast cancer: a meta-analysis. Oncotarget 8:75389-75399. https://doi.org/10.18632/oncotarget.17853

58. Gong WJ, Zheng W, Xiao L, Tan LM, Song J, Li XP et al (2016) Circulating resistin levels and obesity-related cancer risk: a meta-analysis. Oncotarget 7:57694-57704. https://doi.org/10.18632/oncotarget.11034

59. Zeng Y, Tang CH, Wang Y, Lu HJ, Huang BF, Wang Q et al (2020) Combined high resistin and EGFR expression predicts a poor prognosis in breast cancer. Biomed Res Int 2020:8835398. https://doi.org/10.1155/2020/ 8835398

60. Lee YC, Chen YJ, Wu CC, Lo S, Hou MF, Yuan SS (2012) Resistin expression in breast cancer tissue as a marker of prognosis and hormone therapy stratification. Gynecol Oncol 125:742-750. https://doi.org/10.1016/j. ygyno.2012.02.032

61. Moher D, Liberati A, Tetzlaff J, Altman DG, PRISMA Group (2009) Preferred reporting items for systematic reviews and meta-analyses: the PRISMA statement. PLoS Med 6:e1000097. https://doi.org/10.1371/journal.pmed. 1000097

62. Wan X, Wang W, Liu J, Tong T (2014) Estimating the sample mean and standard deviation from the sample size, median, range and/or interquartile range. BMC Med Res Methodol 14:135. https://doi.org/10.1186/ 1471-2288-14-135

63. Wells GA, Shea B, O'Connell D, Peterson J, Welch V, Losos M et al (2014) The Newcastle-Ottawa Scale (NOS) for assessing the quality of nonrandomised studies in meta-analyses

64. Egger M, Davey Smith G, Schneider M, Minder C (1997) Bias in metaanalysis detected by a simple, graphical test. BMJ 315:629-634. https:// doi.org/10.1136/bmj.315.7109.629

65. Begg CB, Mazumdar M (1994) Operating characteristics of a rank correlation test for publication bias. Biometrics 50:1088-1101

\section{Publisher's Note}

Springer Nature remains neutral with regard to jurisdictional claims in published maps and institutional affiliations.

\section{Submit your manuscript to a SpringerOpen ${ }^{\circ}$ journal and benefit from:}

- Convenient online submission

- Rigorous peer review

- Open access: articles freely available online

- High visibility within the field

- Retaining the copyright to your article

Submit your next manuscript at $\boldsymbol{\nabla}$ springeropen.com 